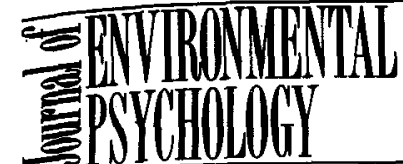

\section{THE PHYSICAL ENVIRONMENT OF STREET CRIME: DEFENSIBLE SPACE, TERRITORIALITY AND INCIVILITIES ${ }^{1}$}

\author{
Douglas D. Perkins*2, Abraham Wandersman†, Richard C. Rich $\ddagger$ and Ralph B. Taylor \\ * University of Utah, $\dagger$ University of South Carolina, \\ $\ddagger$ Virginia Polytechnic Institute and State University, § Temple University, U.S.A.
}

\begin{abstract}
This study systematically examines the physical context of crime on urban residential blocks. A conceptual framework for understanding the relationship of the objective permanent (defensible space) and transient (territorial markers and incivilities) physical environment and the subjective environment to crime is presented. Forty-eight blocks were selected from three working-class urban neighborhoods. Data were obtained from four sources: a telephone survey of 1081 randomly sampled residents, a 15-month follow-up survey $(n=471)$, block-level police records of 1190 crime complaints, and the Block Booster Environmental Inventory-a new procedure for objectively measuring physical signs of disorder, territoriality and the built environment of 576 homes on all 48 blocks. Five different indicators of block crime were used: perceived crime and delinquency, reported serious and 'quality-of-life' crimes, and surveyed victimization rate. All data were aggregated to the block level. Although the various measures of crime were not consistently intercorrelated, objective environmental items correlated more strongly and consistently with the crime indicators than did the subjective environment, even after controlling for the demographic profile of the block. Defensible space features of the built environment, demographics and, to a lesser extent, the transient environment (disorder and territoriality) contributed significant variance to a series of regression equations explaining up to $60 \%$ of the variance in block crime. Implications for environmental criminology and for community policing and crime prevention are discussed.
\end{abstract}

\section{Introduction}

Research on environmental criminology has developed to the point that we now know about many different kinds of physical features and environmental measures that have been linked to crime and deterrence (Newman, 1972; Brantingham \& Brantingham, 1981; Brown, 1987; Taylor, 1987). As studies have narrowed their focus in order to discover finer, more detailed attributes of the environment of crime, however, it is important not to lose sight of the broader theoretical terrain. This article has three main objectives: (1) to present a more comprehensive and integrated framework for understanding how specific features in the physical environment of urban residential blocks are related to 'street' crime; (2) to introduce a new, objective, independent and reliable method for measuring the physical environment of residential blocks in a way that can be usefully related to crime (as well as a variety of other important community demographic, attitudinal and behavioral variables: Perkins et al., 1990, 1992); and (3) to test both the framework and the environmental method for their ability to predict five different indicators of block-level crime.

First, we review the theoretical relevance to crime of such physical environmental domains as the built environment and more transient symbols of disorder and territoriality. Next, the ecological validity of the street-block level of conceptualization is considered. The section concludes with a review of some of the major issues in measuring both crime and the environment.

\section{A Framework of Environmental Factors Related to Street Crime}

In the present study, street crime is seen as an outgrowth of neighborhood conditions. Some of these conditions are demographic, such as low levels of income, home ownership and residential stability. These and other demographic variables will be tested and controlled in the present analysis. But they are not the main focus of the study. We believe that certain, more permanent physical characteristics 
of the community serve as direct deterrents to crime while others are somewhat more ephemeral and operate more subtly as symbols of order or disorder. In other words, these environmental characteristics are cues to either territorial and lawful or antisocial and lawless behavior. These cues are filtered through the subjective perceptions of both residents and potential offenders.

Thus, our theoretical framework is organized around two dimensions: physical features are (1) more or less temporally stable (i.e. permanent or transient) and (2) more or less objectively or subjectively perceived. First, on the stability dimension, the more permanent, built environment consists of architectural and urban planning features falling under the general rubric of 'defensible space' (Newman, 1972), that may deter crime through (1) erecting barriers, (2) improving opportunities for the natural surveillance of public space and (3) facilitating a shared proprietary sense toward public space. The more transient physical environment of the block includes both territorial markers (e.g. plantings and decorations) and signs of disorder, or 'incivilities' (e.g. litter, graffiti). Similar to the third function of defensible space, these transient features send powerful symbolic messages about the extent of control and privacy being exercised in different areas.

The second dimension, or stage, in the framework is the influence of subjective perceptions of the permanent and transient environment, which may vary in its connection to objective reality. The present study will examine resident perceptions of territorial functioning and physical incivilities. Although offenders' perceptions of barriers may be a direct deterrent to crime, the framework suggests that most of the crime prevention effects of offender and resident perceptions of defensible space are felt through residents' territorial behavior. We shall now review the relation of these three kinds of environmental features with crime in more detail.

\section{The built environment}

The literature on spatial and architectural influences on crime has focused mainly on larger design elements such as building and street layout. Jacobs (1961) first proposed the idea that urban planning could help revitalize community street life and thereby reduce street crime. She observed that the safest areas appeared to be buildings that were physically oriented for natural surveillance by residents (including streets that are visible from first-floor windows and not so wide that neighbors across the street would not notice a prowler) and public and private spaces that were delimited into clearly differentiated domains. Street width may also be seen as an indicator of block or neighbor. hood 'permeability' to traffic (including offenders and other 'strangers'), which has been associated with burglary (White, 1990) and other crime rates (Greenberg \& Rohe, 1984; Fowler \& Mangione, 1986).

Newman (1972) expanded 'defensible space' theory by suggesting that certain design features, such as barriers to discourage entry and divide public space into manageable zones, would encourage a greater proprietary interest in the community. This, in turn, would reduce crime and fear. The anti-crime design feature most associated with Newman is keeping the size of public housing buildings small and low-rise to elicit more social contact, familiarity. and social control among residents (Newman \& Franck, 1982). Although the effect of building size on crime will be considered in the present study, block size will be controlled along with the demographic variables.

Early defensible space theory tended to concentrate on large, 'macro' features of the architectural environment. Design elements that aid surveillance or act as barriers, but are smaller and may be added to buildings and landscape, may be termed 'microdefensible space'. 'Real' barriers include physical objects such as walls, fences or security bars, that impede either entry to or egress from the criminal's target. 'Symbolic' barriers, such as low walls or railings do not impede access but symbolize where public space ends and private space begins. Surveillance opportunities are enhanced by such environmental features as outside lighting, unobstructed sight lines, and places to sit outdoors (MacDonald \& Gifford, 1989).

Although one study found defensible space to have a limited influence on the residential social climate (Merry, 1981) and another study found different forms of defensible space to have different (both positive and negative) effects on perceived crime and disorder (Perkins et al., 1992), other research has found certain defensible space features to be related to lower fear, higher informal social control, and a lower crime rate (Taylor et al., 1984; Fowler \& Mangione, 1986; Coleman, 1989).

The community of interest to Newman and other macro-defensible space researchers (e.g. Merry, 1981; Coleman, 1989) has been public housing projects. The present study is one of the first to examine how applicable both micro- and macro? defensible space variables are to non-public housing developments. We also focus on non-residential 
property differently than did Jacobs and Newman, who argued for juxtaposing residential areas with intensively used non-residential space (in order to provide more 'eyes and ears'). As explained below, our concern is that commercial, vacant and other non-residential property may represent a gap in resident territorial functioning and may attract social and physical incivilities as well as potential offenders to the block.

\section{Territorial markers}

Brown and Altman (1981) applied the social psychological concept of privacy regulation to neighborhood crime and crime prevention. A key aspect of their formulation was the distinction between shared 'public' and 'secondary' territories and 'primary' territories. Primary territories are mainly in or very near one's home and constitute the main settings of the present study. It is functionally and symbolically central to one's everyday life and so one is more likely to defend one's primary territory.

Taylor (1988) defines the concept of territorial functioning' as a broad class of transactions between the environment and group or individual cognitions, behaviors and sentiments with the primary purpose of controlling behavior in a particular place. Territorial functioning depends in part on the presence of physical markers which carry non-verbal messages of ownership, monitoring and protection, and a separation between one's self or family and 'outsiders' (Taylor \& Stough, 1978; Brown \& Altman, 1983; Shumaker \& Taylor, 1983).Territorial markers include the planting of gardens, trees, and shrubs, or the display of yard decorations or name signs as a way of beautifying and 'personalizing' one's home or community.

There is considerable variation in human territorial functioning across and within neighborhoods. For example, a breakdown in informal social control is expected near the territorial boundaries of an area and other gaps in the residential topography, such as parks, playgrounds and public buildings (Merry, 1981; Taylor, 1988). This may be due to the prevalence of strangers along boundaries and gaps (which reduces the likelihood of bystander intervention and increases the chances that one of the strangers is a malefactor).

Markers have been found to be associated with residents' perceptions of fewer signs of community social disorder and crime problems (Craik \& Appleyard, 1980; Brower et al., 1983). This relationship is significant even after controlling for socioeconomic status and home ownership (Perkins et al., 1992).
Similar to defensible space, territoriality may deter crime through improvements in community social cohesion. Territoriality has been empirically related to greater social interaction, sense of community (Becker, 1977), general social cohesion (Brown \& Werner, 1985), less fear of crime (Taylor et al., 1984), and even with fewer property violations, especially burglary (Becker, 1977; Brown \& Altman, 1983).

\section{Incivilities}

As symbols of social disorder, incivilities are central to a new and influential theory explaining the devolution of urban communities into havens for delinquents, criminals and drug traffic. Perhaps the most obvious signs of incivility are social: prostitutes, drug addicts, youth gangs or homeless people loitering on the street. Physical incivilities may also send a powerful message of lawlessness. They can be either active and deliberate (such as graffiti and vandalism) or passive and inadvertent (such as litter or unkempt housing). Specific incivilities have been empirically linked to residents' fear of crime (Reppetto, 1974; Ahlbrandt \& Cunningham, 1979; Skogan \& Maxfield, 1981; Taylor et al., 1984). The broader theoretical links between incivilities, resident behavior and ultimately street crime (Wilson \& Kelling, 1982; Skogan, 1990) have barely begun to be empirically tested, however. Furthermore, police efforts to reduce fear and crime through incivility reduction have met with mixed results (Greene \& Taylor, 1988).

Results from the only studies that used objective measures (see Measuring the Physical Environment, below) of physical incivilities were mixed. Consistent with survey data from other cities (Taylor \& Hale, 1986), Taylor et al. (1985) found that the relationship between fear and objective indicators of incivilities depended largely on two communitylevel factors: socio-economic status and confidence in the future of the neighborhood. Incivilities were significantly related to fear only in poor and deteriorating neighborhoods. However, the size of the correlations may have been limited by the relatively low incidence of incivilities in some neighbourhoods and/or by the procedure in which raters remained in their cars throughout observation.

In contrast to those findings, Maxfield (1987) found that objective measures of physical neighborhood decay were related to higher fear levels in both the U.S.A. and the U.K, and that the effects were often greater than for perceived vulnerability or victimization. Similarly, in a recent study using an on-foot block environmental inventory, Perkins 
et al. (1992) found significant block-level links between perceptions of crime and disorder and objective physical incivilities. Thus, there is some evidence of the importance of incivilities at least to crime-related perceptions, if not yet crime itself.

\section{The subjective experience of the environment}

According to our framework, each of the three types of crime-related environmental cues is filtered through the subjective perceptions of those cues. For example, potential offenders must perceive defensible space as risky for it to affect their behavior. Although the present study does not focus on perceived defensible space, much of the deterrent effect of both defensible space and territorial markers is reputed to operate through the heightened territorial behavior of residents. Therefore, we include community territorial functioning in this stage of our conceptual framework. Two kèy components of territorial functioning are place attachment and informal social control. When residents' attachment to their homes and communities is disrupted by crime or other threats, they are stripped of their most basic anchors of haven and identity (Brown \& Perkins, 1992). To counteract such a threat, informal social control may be used by residents in an attempt to regulate everyday public behaviors and physical conditions within the bounds of their community. Low informal social control has been linked to increased resident turnover, loss of local commerce, crime and deterioration of the physical environment (Rich, 1980; Skogan \& Maxfield, 1981; Greenberg \& Rohe, 1986; Hunter, 1987).

Resident perceptions of incivilities are a key component of the disorder theory of crime and community decline (Wilson \& Kelling, 1982; Skogan, 1990). This theory basically holds that as incivilities proliferate, residents notice and accurately perceive those problems and lose confidence in the future of their neighborhood and in both formal (e.g police) and informal social controls. As residents become more fearful and minor lawbreaking goes unpunished, more serious crime increases and the neighborhood slides out of control (Skogan, 1990; Perkins et al., 1992).

\section{Measurement Issues}

\section{Measuring the physical environment}

In spite of the considerable theoretical and empirical attention paid to features of the physical environ- ment associated with neighborhood crime and fear, few researchers have measured the physical environment directly. Instead, they have focused almost exclusively on residents' passive and sub. jective perceptions of disorder and simply assumed that they were an accurate reflection of reality and were not contaminated by residents' fear of crime and other emotions about their community (e.g. Lewis \& Maxfield, 1980; Skogan \& Maxfield, 1981; Lewis \& Salem, 1985). In addition, the possibilities of method bias (the tendency for measures taken from a common data source to covary) or survey measurement error are rarely considered.

Objective measurement of the environment is rarely done because to do it carefully takes more time than simply asking residents how much of a problem' certain local conditions are. Independent and systematic environmental assessment methodology is, however, important for reasons of validity and reliability. The evidence for the accuracy of residents' subjective appraisal of physical incivilities is mixed, even when using similar objective and subjective measures (cf. Perkins et al., 1990, 1992). A practical justification for greater use of objective measures is that, by pointing to specific crime and fear cues in the physical environment, they may lead to more effective efforts to reduce crime and fear through environmental planning, design and maintenance.

A variety of procedures have been used to objectively assess community physical features, including site-based assessments on foot (Newman, 1972; Craik \& Appleyard, 1980; Brown \& Altman, 1983 ) or by automobile (Taylor et al., 1985) and judgements of drawings (Brower et al., 1983) and of photographic slides of actual street scenes (Craik \& Appleyard, 1980) and properties (Taylor et al., 1984). The latest procedure is focused on both blockand property-level assessments of defensible space, territoriality, and incivilities on both residential and non-residential properties. It is conducted on foot, includes a field listing of all occupied housing units on the block has been found to exhibit strong interrater reliability and predictive validity (Perkins et al., 1992). This is similar to the method we use in the present study.

\section{Measuring crime}

Crime rates based on police records of complaints or calls for service and those based on victimization surveys are prone to measurement problems (O'Brien, 1985). Although record keeping and analysis of crime data are steadily improved, official police 
data continue to be of questionable reliability and validity (Harries, 1974). Certain crimes, such as rape are significantly under-reported. Changes or differences in reported crime may be due to differential reporting practices, political exigencies, or demographic trends. A temporary 'increase' in rates may even result from more effective crime control (as the rate of crime reporting increases). Furthermore, crime statistics typically reflect only 'serious' (FBI Part 1 'index') offenses and ignore a host of minor offenses as well as fear of crime and community disintegration. Finally, crime rates are usually available only for an entire city or precinct, which can obscure crime patterns at the block level.

Surveyed victimization rates are considered more accurate than official crime rates, but even the best of these, the annual National Crime Survey, suffers from validity and reliability problems (Levine, 1976; O'Brien, 1985). Personal crime victimizations, such as rape and domestic assault, are not much more likely to be reported to civilian interviewers than to police. Victims may be motivated to report or even exaggerate property crimes to the police for insurance purposes; but there is no monetary motivation for reporting losses in a victimization survey. Other surveyed victimization rates may be over-estimated due to problems of recall (e.g. forward 'telescoping', or remembering salient events as more recent than they actually occurred).

Given the relatively low individual-level incidence of serious crimes, a third approach to estimating crime-related problems in an area has been to ask local residents for their perception of such problems. Subjective measures may not be an accurate estimate of either reported crime or victimization, however. Thus, the present study uses the triangulation of different data sources, which is recommended to cross-validate crime estimates (O'Brien, 1985).

\section{The importance of residential blocks}

The present research focuses on the street block (not to be confused with census block) level of analysis. We define a block as the properties on both sides of a single residential street with cross streets (or a dead end) serving as block boundaries. Although the criminology literature has begun to focus more on the community (not only the community environment, but community development, community policing and community crime prevention), as opposed to the individual criminal or victim, it has generally ignored the residential block level of analysis. The block deserves more attention as an important social unit for community research.
Block boundaries are less ambiguous to residents than are neighborhood boundaries and more easily defined for research purposes (Taylor, 1988). Since blocks are more culturally homogeneous than larger units, such as neighborhoods and police precincts, block residents are more likely to know each other and share the same concerns (Gans, 1967). Furthermore, processes of informal social control and territoriality (Taylor et al., 1984), formally organized community crime prevention (Taylor \& Gottfredson, 1986), and citizen participation, generally (Yates, 1973), may operate more successfully in the familiar face-to-face setting of the block than in a neighborhood or other ambiguous and anonymous social unit. Crime and fear-related environmental cues are hypothesized to be felt more acutely by residents on the block than on the neighborhood level (Taylor, 1987). For all these reasons, we suggest that the block level of analysis has a high degree of ecological validity and is the best social unit to test most contextual theories of street crime.

\section{Hypotheses}

Defensible space features are expected to deter crime by encouraging residents' use of, and control over, public areas of the community and by raising offenders' risk perceptions. Another aspect of the built environment-the presence of commercial, vacant and other non-residential property-indicate territorial gaps and are expected to attract crime and youth gang activity. The display of territorial markers and the absence of physical incivilities are predicted to reduce crime by transmitting symbolic messages of territorial functioning and social control. Because the subjective perceptions of those controls and incivilities are imperfectly related to their objective existence, resident survey-based indicators of block territorial behaviour and incivilities will also be examined. They should be related to crime in the same way as their objective counterparts, only more so, given that perceptions are one step closer to criminal and crime prevention behavior.

Demographic variables are being treated as control variables in the present study. Blocks with greater household income, home ownership and length of residence have a greater material stake in property and engage in more territoriality and crime prevention (especially individual, 'target hardening' protections; Perkins, 1990) and are expected to have less crime. With regard to racial composition, the literature on urban crime patterns suggests that minority blocks should have more crime. One other 
block-level demographic variable can be derived from the environmental assessment, estimated block population. Bystander non-intervention theory (Latane \& Daley, 1969) predicts that size should be positively related to crime.

\section{Methods}

The present study was conducted as part of the Block Booster Project, an action study of the social and crime control effects, organizational dynamics, and viability of urban residential block associations. The present data were obtained from four sources: (1) an observer-conducted assessment of the physical environment of 48 blocks; (2) a telephone survey of randomly selected residents of those blocks; (3) a 15-month follow-up survey and (4) police records of major and minor crime complaints on those blocks. All four data sets were aggregated to the block level of analysis for the present study.

\section{Site selection}

Neighborhood selection. Twenty-one potential sample neighborhoods throughout New York City were selected on the basis of having increasing robbery and burglary rates (to ensure that crime would be a potentially relevant issue), according to the latest available police reports, and also on the basis of degree of community organization. Letters with return cards were sent to 1521 block association leaders in these 21 neighborhoods to assess their willingness to participate in the larger project. Based on the response, three culturally disparate neighborhoods were selected: (1) a predominantly white, middle- and working-class Brooklyn neighborhood; (2) a working-class neighborhood containing a mixture of Caribbean-born blacks and Americanborn blacks and whites (also in Brooklyn); and (3) a somewhat more dispersed section of Queens that is predominantly black and ranges from low-income to working-class. Neighborhoods in Manhattan were avoided since the density of its population may make it atypical of other U.S. cities.

Block selection. Criteria for selecting the 48 blocks from these three neighborhoods were that they be predominantly residential in land use and of moderate population density. Site visits were made to each potential study block to verify that they met these criteria and one another: both the physical layout and land use pattern on the blocks and their adjacent blocks had to be typical of the neighbor- hood as a whole (e.g. if the neighborhood street pattern was a grid with the commercial concentration at the boundary, selected blocks fit that pattern-i.e. with small stores on the corners onlyand were not adjacent to the central business district). The dwellings were small, single-family houses $(61 \%)$, duplexes (32\%), or small (four-to-tenunit) apartment buildings (7\%).

Since the overall project focused on block associations, organized and unorganized blocks were selected in a roughly two-to-one ratio, respectively. The residents of organized and unorganized blocks did not differ significantly in length of residence, race, income, home ownership, estimated block population, or the presence of commercial or other nonresidential property.

\section{Instruments}

\section{Independent variables}

Initial telephone survey. The initial survey of block residents was conducted in the spring of 1985 . It took approximately 20 minutes to complete and contained 126 items, including residents' perceptions of block conditions and informal social control and demographic variables. Scales were computed using standardized items to make all item response ranges comparable. The present analyses use aggregated block-level means on each variable. One block was inadvertently excluded from the survey but was included in the objective environment-crime analyses due to the small $n$ at the block level.

Survey sample. For each block, between 15 and 90 sample phone numbers were randomly selected from the 'criss-cross' directory. The initial sample frame for all 47 blocks was 2791 potential respondents, 909 of whom were never contacted (due to either being unreachable or not needed). Of the remaining 1882, 1081 (57\%) completed the survey. The number of respondents per block ranged from 10 to 41 with a mean of 23 . Sixty-five per cent of the respondents were female; $47 \%$ were black, $47 \%$ were white and the rest were Hispanic, Asian or 'other'. Approximately two-thirds of the blocks (which tend to be smaller) are predominantly black and the rest (larger blocks) are predominantly white. Sixty-two per cent owned their home. Of the renters, approximately $60 \%$ lived in apartment buildings and the rest lived in private homes. Sixty per cent of the households reported having no children at home. Other demographics can only be interpolated since broad response categories were used. The sample was evenly spread over all adult age categories, with the mean being approximately 
42-years-old; the median estimated annual family income was approximately $\$ 19,000$ (1985); and the median length of residence was approximately 9.5 years.

Demographic variables include income level, racial composition (proportion of non-white respondents on the block), community stability (average length of residence), and proportion of home owners. One item from the environmental inventory (below) was also used as a demographic variable: estimated block population (i.e. the number of buildings on the block multiplied by the approximate number of units per building).

Perceived incivilities (alpha $=0.65$ ) is a measure of the respondents' estimates of the seriousness of the following, non-criminal physical, quality-of-life problems on the block: unkempt property, poor sanitation services and litter.

There are two measures of territorial functioning. Informal social control (alpha $=0.59$ ) assesses the likelihood of a neighbor doing something about three different types of hypothetical 'threats' or 'incivilities', including trash, vandals and a suspicious stranger. Separate from this scale (based on a principal components analysis) is another territorial functioning item measuring the degree to which 'neighbors on the block watch after each other'.

Environmental inventory. ${ }^{3}$ The Block Booster Environmental Inventory consisted of detailed and systematic, in-person observations by trained raters (see Table 1). The procedure was conducted in the summer of 1985 on all study blocks in order to examine: (a) physical signs of social disorder or 'incivilities' (e.g. the presence of vandalism, litter, graffiti, or dilapidated exteriors due to lack of property maintenance; social incivilities were excluded because obvious signs of serious social disorder, such as overt drug dealing and prostitution, are generally so sporadic or time-of-day specific that they may be missed or overstated by a single visit to a block); (b) territorial symbols (e.g. block watch signs and alarm stickers, evidence of dogs, such home 'personalization' signs as family names on doors or lampposts, and beautification efforts, such as plantings and yard decorations); and (c) the built environment (e.g. the amount and type of nonresidential property on the block and 'defensible space' features such as opportunities for passive street surveillance, street and private lamps, places to sit outdoors, and barriers on and around the property). Barriers included fences, gates, walls, hedges, and bars on windows (Figure 1).

Raters were blind to block crime status. The procedure took 30 to 60 minutes to complete for a given block, depending on the block's size. A single rater walked around the block once filling out the blocklevel assessment indicating street width in lanes and noting building attachment and size category. The rater also recorded all public lighting, damage or graffiti on public property, abandoned buildings and cars, type of non-residential buildings, public gardens, playgrounds, and block identifiers or 'block watch' signs. To evaluate incivilities, territoriality, and defensible space with sufficient precision, the rater walked the block a second time to fill out a 20-item checklist on every third property until 12 properties per block were assessed. Thus, the property checklist items are block-level aggregates based on an individual-level sample of 564 properties.

Dependent variables: block-level crime indicators. Data triangulation is important due to problems of reliability and validity with most indexes of area crime. Therefore, we adopted five different indicators of block street crime, all based on crime events or perceptions during the year following the initial data collection (of independent variables): resident perceptions of delinquency problems, resident perceptions of crime problems, a resident criminal victimization survey, and police reports of 'qualityof-life' and 'serious' crimes.

Follow-up telephone survey. The first three indicators are from a (15 months post-survey I, 9-11 months post-environmental assessment) follow-up telephone survey of 471 households (438 had participated in the initial survey, 33 were replacements) on 44 of the study blocks. ${ }^{4}$ The first two derive from a varimax-rotated block-level principal components analysis of perceived crimerelated problems on the block.

Perceived delinquency problems (alpha $=0.81$ ) is a measure of the respondents' estimates of the seriousness of three specific potential delinquency problems on the block: vandalism, drug dealing, loitering youths.

Perceived crime problems (alpha $=0.76$ ) is a measure of the respondents' estimates of the seriousness of crime problems on the block (robbery, assault, burglary, direction crime is headed-better or worse).

Household criminal victimization was computed as follows: block mean from self-reported burglary, car theft, larceny, robbery or (non-domestic) assault victimization incidents (per household) on the block during the previous 12 months. On the average block, the mean number of criminal victimizations per respondent households in the previous year was 0.49 . 
TABLE 1

Block environmental variable descriptive statistics and pretest reliability*

\begin{tabular}{|c|c|c|c|c|c|}
\hline Variable & Range & Mean & $\begin{array}{l}\text { 3-way } \\
\text { S.D. }\end{array}$ & $\begin{array}{l}\text { \% Exact } \\
\text { inter- } \\
\text { agreement }\end{array}$ & $\begin{array}{l}\text { Mean } \\
\text { inter- } \\
\text { rater } r\end{array}$ \\
\hline \multicolumn{6}{|l|}{ Block-level variables } \\
\hline $\begin{array}{l}\text { Built environment } \\
\text { Street width (in lanes) }\end{array}$ & $3-5$ & $3 \cdot 42$ & 0.54 & 100 & 1.00 \\
\hline Total buildings & $22-108$ & $57 \cdot 33$ & $22 \cdot 76$ & 70 & 0.99 \\
\hline Proportion attached buildings & $0-0.99$ & 0.40 & 0.39 & 60 & 0.99 \\
\hline Total one-family houses & $0-88$ & $35 \cdot 33$ & 21.48 & 60 & 0.99 \\
\hline Total 2- or 3-unit buildings & $0-75$ & $18 \cdot 52$ & $18 \cdot 14$ & 77 & 0.98 \\
\hline Total multi-unit (4+) buildings & 0-16 & $3 \cdot 10$ & $4 \cdot 38$ & 93 & 0.97 \\
\hline Vacant lots & $0-8$ & 0.27 & 1.26 & 100 & 1.00 \\
\hline Boarded abandoned buildings & $0-2$ & 0.25 & 0.53 & 100 & 1.00 \\
\hline Stores & $0-4$ & 0.98 & 1.04 & \multirow{2}{*}{\multicolumn{2}{|c|}{$\begin{array}{l}\text { (not pretested) } \\
\text { (not pretested) }\end{array}$}} \\
\hline Other non-residential buildings & $0-8$ & $1 \cdot 27$ & $1 \cdot 80$ & & \\
\hline \multicolumn{6}{|l|}{ Incivilities } \\
\hline Graffiti on public property & $0-47$ & $14 \cdot 15$ & 9.02 & 27 & 0.90 \\
\hline Proportion public graffiti & $0-0.81$ & $0 \cdot 26$ & 0.15 & & \\
\hline \multicolumn{6}{|l|}{ Territoriality } \\
\hline Block or 'block watch' signs & $0-12$ & 0.94 & 2.59 & 100 & $\dagger$ \\
\hline \multicolumn{6}{|c|}{ Property-level variables (per 12 properties) } \\
\hline $\begin{array}{l}\text { Built environment } \\
\text { Visibility of } 1 \text { st floor windows }\end{array}$ & $9-12$ & 11.29 & 1.30 & 88 & 0.50 \\
\hline Barrier on property & $2-12$ & 8.92 & $2 \cdot 65$ & \multicolumn{2}{|c|}{ (not pretested) } \\
\hline Barriers around property & $0-12$ & 3.96 & $3 \cdot 13$ & 96 & 0.91 \\
\hline Public (street) lighting & $2-12$ & 5.98 & 2.52 & 88 & 0.83 \\
\hline Outdoor private lighting & $2-12$ & 8.69 & 2.45 & 85 & 0.79 \\
\hline Front gates & $0-11$ & 4.83 & 2.96 & 96 & 0.93 \\
\hline Bars or gates on windows & $0-9$ & $2 \cdot 63$ & $2 \cdot 13$ & 94 & 0.73 \\
\hline Bench, stoop (outdoor seating) & $7-12$ & 11.08 & 1.24 & 92 & 0.68 \\
\hline \multicolumn{6}{|l|}{ Incivilities } \\
\hline Litter on/near property & $0-3$ & $0 \cdot 71$ & 0.97 & 92 & 0.70 \\
\hline Graffiti on property & $0-7$ & 0.69 & 1.31 & 90 & 0.67 \\
\hline Exterior dilapidation & $0-3$ & $0 \cdot 62$ & 0.73 & 85 & 0.40 \\
\hline \multicolumn{6}{|l|}{ Territoriality } \\
\hline Occupied building & $10-12$ & 11.71 & 0.50 & 98 & $0 \cdot 80$ \\
\hline Dogs (dog house, beware sign) & $0-5$ & 0.71 & 1.05 & 92 & 0.81 \\
\hline Personalized signs & $0-8$ & 1.98 & 1.83 & 77 & 0.53 \\
\hline Private trees, shrubs, garden & $1-12$ & 9.98 & $2 \cdot 85$ & 96 & 0.86 \\
\hline Public plantings & $2-10$ & $5 \cdot 88$ & $2 \cdot 18$ & 90 & 0.86 \\
\hline Security/alarm signs on property & $0-4$ & 0.79 & 0.94 & 94 & 0.72 \\
\hline \multirow[t]{2}{*}{ Block or block watch signs } & $0-5$ & 0.52 & 1.07 & 100 & + \\
\hline & & & \multicolumn{2}{|r|}{ Mean $=87$} & 0.79 \\
\hline
\end{tabular}

* The $n$ of blocks for the range, mean and standard deviation is 48. Inter-rater reliability was computed on 10 separate pretest blocks. The coefficients represent the percent exact agreement among three raters and the mean of the three inter-rater (intra-class) correlations.

$\dagger$ Correlation cannot be computed due to lack of variance in the pretest. 

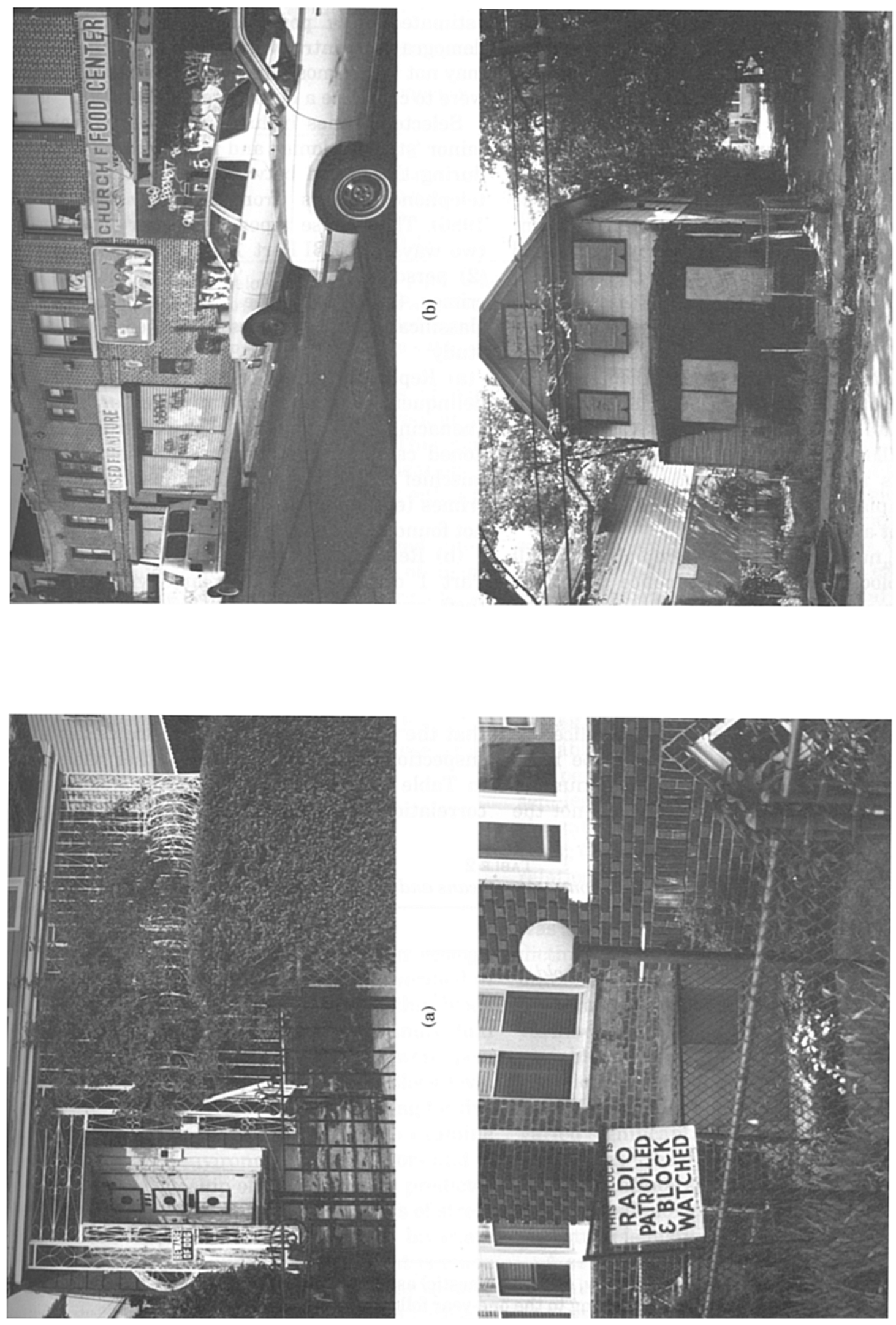

$\overline{0} \cdot \overline{0}$

政

量

莎

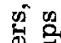

s.

중

중

के

\&.ㅁำ

?ำ

ฮ.

50.5

क동

넝 겅 혁

은

苍范

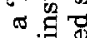

枒

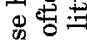

旁安

.

들

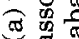

둥

空

능한

要

\&

ธै

구을

क

品

당

+ :

为

粦击

요요

응

密

东

疋苍

壱要

- $\quad$ 节范

(9)

象 운

हैํํ을

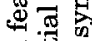

중

\%

要

岁

要

뭉

究

空

-

-1.

果

总焉 
Official police crime data. Crimes reported to police were collected and analyzed at the block level of every block in the study. This differs from most previous studies which rely on aggregated precinct or city-level data (if police data are available). Descriptive statistics for block crime complaints and victimization rates can be found in Table 2 and dependent variable intercorrelations in Table 3.

Police records from five precincts (one of the study neighborhoods overlapped three different precincts) were examined and coded by six trained coders for crimes occurring on any of the 48 blocks in the study. The source of the crime data was the New York Police Department Crime Complaint Index Form, which summarizes every detailed Crime Complaint form that is filed. If the location or nature of the complaint was unclear from the Index, coders consulted the corresponding Crime Complaint Form. The Index is filled out at each precinct as complaints are filed. It includes both citizeninitiated complaints as well as those filed by an officer without a citizen complaint.

The mean number of crime complaints on all blocks (per block) filed with the police was 24.8. Reported crime was left as the total number of complaints on the block over the 15 months prior to the follow-up survey. It was not converted to a per capita rate for two reasons: (1) unlike victimization, which often goes unreported (to neighbors as well as the police), the overall number of times police are seen responding to calls on a block may be more important to residents than the per capita number of times. (2) Residents of a given block are not the only victims of crime on that block and so the estimated block population (which is one of the demographic control variables used in the analysis) may not be the most appropriate denominator if one were to calculate a block-level crime rate.

Selected crimes included all types of major and minor 'street' felonies and misdemeanors occurring during the period between and including the two telephone surveys (from February 1985 to July 1986). The offense types were later categorized in two ways: (1) FBI Part 1 and 2 classification; and (2) personal, property, 'quality of life' and other crimes (similar to the National Crime Survey classifications). Two types were used in the present study:

(a) Reported 'quality-of-life' crimes included such delinquent acts as narcotics sales or possession, 'menacing', 'harassment', criminal trespass, abandoned cars, car tampering, and general 'criminal mischief'. This category could have included other crimes (e.g. loitering, prostitution), but these were not found in the records.

(b) Reported 'serious' crimes included all FBI Part I crimes: Burglary, larceny, robbery, auto theft, arson, assault, rape, criminal homicide.

The high correlations between the two types of reported crime may be as much of an indication that confidence in the police, and thus a willingness to report any type of crime, varies geographically as that the different types of crime are closely linked. Inspection of scatterplots of the other relationships in Table 3 reveals a somewhat clearer pattern of correlation on low-crime and low-victimization-rate

TABLE 2

Crime and victimization ranges, means and standard deviations

\begin{tabular}{|c|c|c|c|}
\hline Variable & Range & Mean & S.D. \\
\hline \multicolumn{4}{|c|}{ Criminal victimization on block (number per household)* } \\
\hline Victimizations & 0.00 to 1.90 & 0.49 & 0.41 \\
\hline Burglaries or attempts & 0.00 to 0.71 & 0.15 & 0.18 \\
\hline Car thefts or attempts & 0.00 to 0.40 & 0.09 & 0.11 \\
\hline Larcenies or attempts & 0.00 to 0.70 & 0.15 & 0.17 \\
\hline Robberies or attempts & 0.00 to 0.44 & 0.07 & 0.12 \\
\hline Assaults or threats & 0.00 to 0.63 & 0.04 & 0.11 \\
\hline \multicolumn{4}{|l|}{ Reported crimes on block $\dagger$} \\
\hline Total number of crime complaints & 1 to 62 & $24 \cdot 8$ & $13 \cdot 8$ \\
\hline (FBI Part 1) 'Serious' crimes & 0 to 36 & $13 \cdot 6$ & 7.9 \\
\hline (NCR) 'Personal' crimes & 0 to 26 & $5 \cdot 4$ & 4.7 \\
\hline (NCR) 'Household' (property) crimes & 0 to 29 & 9.9 & $6 \cdot 0$ \\
\hline 'Quality-of-life' (delinquency) crimes & 0 to 15 & 4.4 & 3.4 \\
\hline
\end{tabular}

* Block mean burglary, car theft, larceny, robbery, or (non-domestic) assault victimization incidents (per household) on the block during the previous 12 months, according to the one-year follow-up survey: $n$ of blocks $=44$.

$\dagger$ Mean number of crime complaints on the block (per block) filed with the police, in FBI and National Crime Survey categories, during the previous 15 months, at the time of the one-year follow-up survey. $n$ of blocks $=48$. 
TABLE 3

Block-level Pearson and partial correlations among crime indicators*

\begin{tabular}{lccccc}
\hline & \multicolumn{2}{c}{ Resident perceptions } & & $\begin{array}{c}\text { Surveyed } \\
\text { victimization }\end{array}$ & \multicolumn{2}{c}{ Reported crime } \\
\cline { 2 - 6 } & Delinquency & Crime & & $\begin{array}{c}\text { Quality- } \\
\text { of-life }\end{array}$ & $\begin{array}{c}\text { Serious } \\
\text { (Part I) }\end{array}$ \\
\hline Perceived delinquency & - & 0.47 & 0.28 & 0.19 & 0.17 \\
Perceived crime & 0.48 & - & 0.24 & 0.05 & 0.12 \\
Surveyed victimization & 0.37 & 0.28 & - & 0.17 & 0.10 \\
Reported quality-of-life crime & 0.07 & -0.07 & 0.12 & - & 0.75 \\
Reported serious crime & 0.23 & 0.19 & 0.09 & 0.73 & - \\
\hline
\end{tabular}

* Pearson correlations are below the diagonal. Fifth-order partial correlations controlling for all of the demographic variables shown appear above the diagonal. Pair-wise $n$ of blocks ranges from 44 for victimization and resident perceptions to 48 for reported crime. Two-tailed significance levels at $n=44$ are as follows: $r=0.19(p<0.20)$, $r=0.25(p<0.10), r=0.29(p<0.05), r=0.37(p<0.01)$.

blocks. However, blocks with high rates of surveyed victimization do not necessarily have a great amount of reported or perceived crime. This may reflect the fact that even serious victimization is something that people do not always report either to the police or to their neighbors.

Otherwise, the small and moderate-sized intercorrelations underscore the importance of using multiple measure of crime. Obtaining divergent outcomes is not unusual in criminal justice research (O'Brien, 1985) and simply reflects the fact that we are dealing with three related although clearly distinct phenomena-experienced victimization, what gets reported to police, and how the wider group of residents of a block perceive those problems (cf. Taylor et al., 1984).

\section{Results}

\section{Approach to data analysis}

The assumption that blocks represent an ecologically valid geo-social unit of analysis was verified in a test which demonstrated strong within-block agreement on the survey variables at the individual level of analysis. Subsequent analyses were performed at the aggregated block level. Block-level Pearson and partial correlations (controlling for five key demographic variables) were used to examine correlations among environmental predictors and to examine the relationship of the individual predictor variables to each of five different indicators of street crime on the block. Scatterplots of all bivariate relationships were examined and comment is made below where just one or a few blocks appear to have an exaggerated influence on the results. A series of multiple regression analyses then test the proposed general framework's ability to predict the crime indicators. Each set was entered hierarchically, in steps consistent with the framework, starting with significant demographic correlates of the dependent variable. Therefore, if objective or subjective environmental variables are related to crime in the partial correlation or regression analyses, it cannot be spuriously due to a demographic effect. Furthermore, these analyses are longitudinal insofar as the five dependent variables are all estimates of block crime during the year following the collection of the objective and subjective environmental data.

Tests of non-independence. Aggregated survey variables (block-level perceived territorial functioning, perceived incivilities and perceived crime) represent legitimate group-level 'climate' constructs if they show: (1) sufficient within-group inter-rater agreement; (2) variance across groups; and (3) predictable relationships with other group or individuallevel variables (Shinn, 1990). The last criterion was tested in a variety of block-level analyses predicting crime (below), citizen participation, and other social climate variable (Perkins, 1990). To test the first two criteria, individual-level analyses of variance were conducted on each initial survey variable comparing the blocks as a group effect. A significant $F$-ratio and large $R^{2}$ value would indicate block dependence for that particular variable. Blocks varied significantly on all of the survey variables in the study. Since individual-level analyses would therefore include significant hidden block-level effects, the rationale for aggregated block-level analyses in this study is justified.

A series of block-level ANOVAs by neighborhood was also conducted to determine whether there are any significant differences on any variables among the three neighborhoods. Although blocks were found 
to be neighborhood-dependent on most variables, adjusting from demographic covariates substantially reduced the neighborhood effects. For most variables, the effect became non-significant. This indicates that most of the differences between the neighborhoods are due to demographic influences. Since there are only three neighborhoods in the study and since the source of most of the neighborhood variance clearly resides in the demographic variables, which are controlled, analyses will collapse across neighborhoods.

The problem of limited statistical power. With a sample size of fewer than 50 blocks, statistical power was quite low, especially in the multivariate analyses. Even for bivariate analyses, the blocklevel criterion effect size (for two-tailed significance at $p<0.05$ ) was $r=0.285$. The power (or probability of correctly rejecting a false null hypothesis) at $p<0.05$ (two-tailed) and $r=0.20$ is only 0.28 . At $r=0.30$, power ratio is 0.55 and only reaches the more desirable power level of 0.82 at $r=0.40$ (Cohen, 1969). One method to compensate for this limitation was to raise the block-level alpha (significance) criterion to $p<0 \cdot 20$. Although this procedure may seem unconventional, it actually represents a slight compromise to the $p<0.25$ criterion recommended by Kenny and Lavoie (1985) when analyzing group-level data. (The aggregated block-level data are actually based on a total 1081 (Time 1) and 471 (Time 2) survey respondents, 576 property ratings and 1190 crime complaints.)

The other method used to increase statistical power was through reduction of the number of predictor variables for use in the multiple regression analyses. This was done by creating principal component composite variables and by selecting only the strongest correlates to represent both the control variables $(r>0.25)$ and each cluster of the theoretical framework (partial $r>0.25$ ). Although this strategy tends to capitalize on chance correlations, we decided that it was justified by the high ratio of environmental correlates to blocks.

Four of the built environment items from the environmental inventory loaded as a single factor. It was clear that this factor was conceptually two different variables and so was divided into: (a) the proportion of attached buildings on the block and the barriers on the property (both are near-home barriers); and (b) narrow street and visible windows (these related to visibility to and across the street). In addition, the presence of stores, schools, and other 'non-residential properties' were combined as one variable.

\section{Correlations among environmental predictors}

Before presenting the results linking crime indicators with physical environmental features, correlations found among the independent variables were noteworthy. As expected, territorial markers (public and private plantings and personalizations) were inversely related to all of the physical incivilities: the more markers on a block, the less graffiti $(r=-0.28)$, empty buildings $(r=-0.31$ ), and litter and dilapidation $(r=-0 \cdot 21)$.

Consistent with Skogan's (1990) and Wilson and Kelling's (1982) theses that incivilities are 'contagious', blocks with empty buildings had significantly more litter and dilapidation $(r=0.43)$ and graffiti $(r=0.43)$. Unlike the results of Perkins et al. (1992), however, the only clear relationship between resident perceptions of incivilities and actual (objective) incivilities is a correlation between perceived incivilities and dilapidation of house exteriors $(r=0.28)$. Controlling for block income, length of residence, home ownership, block population and racial composition, no corresponding perceived and objective incivility items were significantly correlated (dilapidation, $p r=0.14$; litter, $p r=0.11$; vandalism, $p r=0 \cdot 17$ ).

\section{The Physical Environment of Street Crime}

Correlations between demographic variables and crime

Pearson and partial correlations with crime (controlling for block residential stability, racial composition, income, home ownership and block population) appear in Table 4. Each of the five demographic variables was at least moderately related to at least two of the five dependent variables. Residential stability (mean length of residence) was negatively related to perceived crime and delinquency problems, surveyed victimization, and serious reported crime. The proportion of non-white residents was positively related to perceived crime but negatively related to reported 'quality-of-life' crime (e.g. drugs, vandalism). Mean household income was negatively related to perceived delinquency problems and serious crime. Both kinds of reported crime were negatively related to proportion of home owners on the block and positively related to the estimated block population.

\section{Partial correlation between environmental features and crime}

Given the demographic aspects of crime, all five demographic variables were partialled from the 
TABLE 4

Block-level Pearson and partial correlations of environment with crime*

\begin{tabular}{|c|c|c|c|c|c|}
\hline & \multicolumn{5}{|c|}{ Crime indicators } \\
\hline & \multicolumn{2}{|c|}{ Resident perceptions } & \multirow{2}{*}{$\begin{array}{c}\text { Surveyed } \\
\text { victimization }\end{array}$} & \multicolumn{2}{|c|}{ Reported crime } \\
\hline 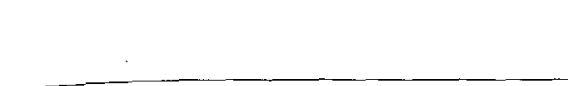 & Delinquency & Crime & & $\begin{array}{l}\text { Quality- } \\
\text { of-life }\end{array}$ & $\begin{array}{l}\text { Serious } \\
\text { (Part I) }\end{array}$ \\
\hline $\begin{array}{l}\text { Demographic controls } \\
\text { Length of residence } \\
\text { Proportion non-white } \\
\text { Income } \\
\text { Home ownership } \\
\text { Block population estimate }\end{array}$ & $\begin{array}{r}-0.41 \\
0.16 \\
-0.24 \\
-0.12 \\
-0.14\end{array}$ & $\begin{array}{r}-0.23 \\
0.28 \\
-0.06 \\
0.10 \\
0.05\end{array}$ & $\begin{array}{r}-0.35 \\
-0.03 \\
0.14 \\
0.02 \\
-0.10\end{array}$ & $\begin{array}{r}-0.12 \\
-0.33 \\
0.15 \\
-0.26 \\
0.42\end{array}$ & $\begin{array}{r}-0.31 \\
0.05 \\
-0.20 \\
-0.22 \\
0.45\end{array}$ \\
\hline $\begin{array}{l}\text { Objective environment } \\
\text { Built environment }{ }^{\dagger} \\
\text { Non-residential property }\end{array}$ & $0.03(0.13)$ & $-0.17(-0.12)$ & $0.04(0.11)$ & $0.66(0.63)$ & $0.55(0.58)$ \\
\hline Commercial property & $0.05(0.22)$ & $-0.28(-0.26)$ & $0.05(0.05)$ & $0.49(0.22)$ & $0.35(0.30)$ \\
\hline Narrow, visible street & $-0.23(-0.34)$ & $-0.28(-0.30)$ & $-0.20(0.05)$ & $-0.01(-0.31)$ & $-0.22(-0.47)$ \\
\hline Street visibility & $-0.37(-0.35)$ & $-0.30(-0.21)$ & $-0.30(-0.38)$ & $-0.01(-0.25)$ & $-0.33(-0.41)$ \\
\hline Average building size & $0.01(-0.07)$ & $0.12(0 \cdot 17)$ & $0.01(0.07)$ & $0.15(0.28)$ & $0.29(0.11)$ \\
\hline Near-home barriers & $-0.16(-0.10)$ & $-0.23(-0.16)$ & $-0.22(-0.40)$ & $0.23(-0.09)$ & $0.10(0.02)$ \\
\hline Bars on windows & $0.06(0.21)$ & $0.04(0 \cdot 20)$ & $-0.12(-0.03)$ & $0.47(0.28)$ & $0.26(0.12)$ \\
\hline Private outdoor lighting & $-0.05(-0.23)$ & $0.22(0.20)$ & $-0.07(0.05)$ & $-0.44(-0.22)$ & $-0.29(-0.14)$ \\
\hline Places to sit outside & $0.03(0.14)$ & $0.20(0.33)$ & $-0.14(-0.07)$ & $-0.25(-0.19)$ & $-0.37(-0.31)$ \\
\hline Dilapidated housing & $0.32(0.37)$ & $0.01(-0.08)$ & $0.26(0.30)$ & $0.04(0.23)$ & $0 \cdot 10(0 \cdot 21)$ \\
\hline Graffiti on public property & $0.04(0.09)$ & $-0.08(-0.24)$ & $0.01(-0.02)$ & $0.43(0.23)$ & $0.53(0.33)$ \\
\hline $\begin{array}{l}\text { Subjective environment } \\
\text { Territorial functioning } \\
\text { Informal social control }\end{array}$ & $-0.31(-0.10)$ & $-0.14(-0.01)$ & $-0.23(-0.19)$ & $0.25(0.29)$ & $0.08(0.31)$ \\
\hline Neighbors watch after each other & $-0.45(-0.31)$ & $-0.20(-0.11)$ & $-0.31(-0.20)$ & $0.16(0.21)$ & $0.08(0.27)$ \\
\hline $\begin{array}{l}\text { Perceived incivilities } \\
\text { Perceived litter }\end{array}$ & $0.09(-0.03)$ & $-0.08(-0.08)$ & $0.13(0.05)$ & $0.20(0.16)$ & $0.19(0.13)$ \\
\hline Perceived dilapidation & $0.23(0.17)$ & $0.15(0.04)$ & $0.05(0.08)$ & $-0.15(0.06)$ & $-0.01(-0.02)$ \\
\hline Perceived vandalism & $0.20(0.08)$ & $0.14(0.15)$ & $0.12(0.12)$ & $0.26(0.21)$ & $0.27(0.08)$ \\
\hline
\end{tabular}

* Fifth-order partial correlations controlling for all of the demographic variables shown appear in parentheses. Pair-wise $n$ of blocks ranges from 44 for victimization and resident perceptions to 48 for reported crime. Two-tailed significance levels at $n=44$ are as follows: $r=0.19(p<0.20), r=0.25(p<0.10), r=0.29(p<0.25), r=0.37(p<0.01)$.

$\dagger$ Composite environmental variables are followed by (indented) component items, not all of which are shown. Non-residential property also includes any office buildings, churches, boarded buildings, parking lots, vacant lots and public gardens and playgrounds. Narrow, visible street also includes the reverse of street width. Near home barriers includes the proportion of attached buildings and barriers on (as opposed to around) the property. 
correlations between objective and subjective environmental features and the various crime indicators. We will highlight some of the associations that remained significant even after controlling for the five demographic influences. With regard to the built environment, the presence of non-residential property on the block (including stores) was related to both quality-of-life and serious reported crime. Unlike other forms of non-residential property, blocks with schools on the corner had significantly higher rates of surveyed street crime victimization. This result is skewed, however, by one of those few blocks having the highest victimization rate of any block.

Streets that are more visible had less crime, according to all five indicators (although the reported quality-of-life crime effect appears to be due to statistical suppression). Real barriers on residents' property were related to less victimization, while bars on windows were related to more reported delinquency and other quality-of-life crimes. Outdoor lighting on private property was associated with less of this type of reported crime. Stoops, porches, benches and other places to sit outdoors were related to worse perceptions of street crime but also to lower amounts of reported serious crime. In fact, every single block with fewer than nine reported serious crimes $(n=11)$ had a place to sit outside virtually every home.

With regard to territorial markers, controlling for block demographics, plantings on private property were related to fewer reported quality-of-life crimes. Unexpectedly, personalizations were related to more of both kinds of reported crime. The more obvious territorial markers, block signs and 'Operation I.D.' and other crime prevention signs, were related only to more reported serious crime.

As predicted by incivilities theory, graffiti on public property was related to reported crime and dilapidated housing was related to perceived delinquency problems and criminal victimization on the block. The amount of litter on the block was related to significantly less reported quality-of-life crime, however. This contradicts the incivilities/disorder theory of crime and delinquency.

Turning to the subjective environment, better territorial functioning (in the form of informal social control) was unexpectedly related to a higher amount of reported crime (although some of this may be a suppression effect). As expected, neighbors watching out for each other was associated with fewer perceived delinquency problems. Resident perceptions of incivilities were largely unrelated to crime. Although perceived vandalism was correlated with more reported crime, the partial correlation suggests that this was at least partly due to demo. graphic factors.

\section{Multiple regression prediction block crime}

To determine which environmental features were most strongly predictive of each of the indicators of block street crime, a series of five multiple regres. sion equations was tested (Table 5). Due to the limited degrees of freedom and statistical power at $n=48$ and $n=44$, only representative demographic variables $(r>0.25)$ and environmental variables $(p r>0.25)$ were entered hierarchically consistent with the framework as predictors of crime.

Perceived delinquency. In Equation 1, mean length of residence was entered first and explained $17 \%$ of the variance in perceived delinquency problems one year later. There are fewer problems perceived on the more residentially stable blocks. In the next stage, two built environmental features added significantly to the equation, mainly due to the influence of street visibility (final beta $=-0.31, p<0.05$ ). Representing the transient environment and territorial functioning respectively, dilapidated housing and (fewer) neighbors watching after one another each contributed $5 \%$ to the variance explained in perceived delinquency problems, independent of the preceding predictors. None of the territorial markers or subjectively perceived incivilities warranted entry in this equation. The adjusted $R^{2}$ for Equation 1 was $0.35(p<0.001)$.

Perceived crime. In Equation 2, the racial com. position of the block shared $8 \%$ of the variance with perceived crime problems one year later. The beta for race was reduced to zero, however, after adding four built environmental variables and $22 \%$ additional variance to the equation. The most important of these were narrow, visible streets (beta $=-0.33$ ), 'other' non-residential property (beta $=-0.41$ ), and stores on the block (beta $=-0.32$ ). The last two effects were the opposite of what was expected and the opposite of what was found for reported crime. No transient or subjective environmental variables warranted entry into this equation. The adjusted $R^{2}$ for Equation 2 was 0.21 ( $p<0.05)$.

Surveyed victimization. Equation 3 predicts surveyed household street crime victimization during the year following the collection of the independent variables. Mean length of residence was entered first and explained $12 \%$ of the variance. 
TABLE 5

Multiple regressions predicting different crime indicators*

\begin{tabular}{|c|c|c|c|c|}
\hline Cluster & $\mathrm{R}^{2}$ increment & Variable & Final beta & Final T-value \\
\hline \multicolumn{5}{|c|}{ Equation 1 (predicting perceived delinquency problems): } \\
\hline Block demographics & $0.167(p<0.01)$ & Length of residence & -0.257 & $-1.83(p<0.10)$ \\
\hline \multirow{2}{*}{ Built environment } & $0.153(p<0.05)$ & Street visibility & $-0 \cdot 311$ & $-2.44(p<0.05)$ \\
\hline & & 'Other' non-residential property $\dagger$ & -0.077 & -0.58 (N.S.) \\
\hline $\begin{array}{l}\text { Transient environment } \\
\text { Territorial functioning }\end{array}$ & $0.053(p<0.10)$ & Dilapidation & 0.217 & $1.71(p<0.10)$ \\
\hline \multirow[t]{2}{*}{ Territorial functioning } & $0.049(p<0.10)$ & Neighbors watch after each other & $-0 \cdot 261$ & $-1.79(p<0.10)$ \\
\hline & \multicolumn{2}{|c|}{$\mathrm{R}^{2}=0.421 ;$ Adjusted $\mathrm{R}^{2}=0.345\left(\mathrm{~F}_{5,38}=5.53 ; p<0.001\right)$} & & \\
\hline \multicolumn{5}{|c|}{ Equation 2 (predicting perceived crime problems): } \\
\hline Block demographics & $0.077(p<0.10)$ & Proportion non-white & -0.001 & -0.00 (N.S.) \\
\hline \multirow{5}{*}{ Built environment } & $0.221(p<0.05)$ & Places to sit outdoors & 0.091 & 0.59 (N.S.) \\
\hline & & 'Other' non-residential property $\dagger$ & -0.411 & $-2.81(p<0.01)$ \\
\hline & & Narrow, visible street & -0.333 & $-1.93(p<0.10)$ \\
\hline & & Stores on the block & -0.324 & $-1.526(p<0.15)$ \\
\hline & $\mathrm{R}^{2}=0.298 ;$ Adj & $\operatorname{ted} \mathrm{R}^{2}=0.206\left(\mathrm{~F}_{5,38}=3.23 ; p<0.05\right)$ & & \\
\hline \multicolumn{5}{|c|}{ Equation 3 (predicting criminal victimization): } \\
\hline Block demographics & $0.119(p<0.05)$ & Length of residence & $-0 \cdot 322$ & $-2.20(p<0.05)$ \\
\hline \multirow[t]{3}{*}{ Built environment } & $0.153(p<0.10)$ & Near-home barriers & -0.181 & -0.11 (N.S.) \\
\hline & & School on the corner & $0 \cdot 274$ & $1.89(p<0.10)$ \\
\hline & & ible street & -0.086 & -0.49 (N.S.) \\
\hline \multirow[t]{2}{*}{ Transient environment } & $0.068(p<0.10)$ & Dilapidation & 0.271 & $1.98(p<0.10)$ \\
\hline & $\mathrm{R}^{2}=0.340 ;$ Adj & ted $\mathrm{R}^{2}=0.253\left(\mathrm{~F}_{5,38}=3.91 ; p<0.01\right)$ & & \\
\hline \multicolumn{5}{|c|}{ Equation 4 (predicting quality-of-life complaints): } \\
\hline \multirow[t]{3}{*}{ Block demographics } & $0.212(p<0.05)$ & Estimated block population & 0.318 & $1.76(p<0.10)$ \\
\hline & & -white & $0 \cdot 157$ & 1.01 (N.S.) \\
\hline & & Hom & -0.336 & $-1.81(p<0.20)$ \\
\hline \multirow[t]{4}{*}{ Built environment } & $0.358(p<0.001)$ & Bars on windows & $0 \cdot 164$ & $1.35(p<0.20)$ \\
\hline & & Total non-residential property & 0.469 & $3.54(p<0.005)$ \\
\hline & & Private outdo & -0.245 & $-1.86(p<0.10)$ \\
\hline & & Average building size & -0.258 & -1.24 (N.S.) \\
\hline \multirow[t]{4}{*}{ Transient environment } & 0.053 (N.s.) & (Home) crime prevention signs & 0.110 & 1.00 (N.S.) \\
\hline & & Personalizations & -0.046 & -0.35 (N.S.) \\
\hline & & Litt & -0.208 & $-1.42(p<0.20)$ \\
\hline & & Private plan & 0.187 & 1.25 (N.S.) \\
\hline \multirow[t]{2}{*}{ Territorial functioning } & 0.005 (N.S.) & Informal social control & $0 \cdot 089$ & $0 \cdot 68$ (N.S.) \\
\hline & $\mathrm{R}^{2}=0.628 ;$ Adju & $\mathrm{d} \mathrm{R}^{2}=0.496\left(\mathrm{~F}_{12,34}=45 \cdot 78 ; p<0\right.$ & & \\
\hline \multicolumn{5}{|c|}{ Equation 5 (predicting serious (FBI Part I) crime complaints): } \\
\hline \multirow[t]{2}{*}{ Block demographics } & $0.247(p<0.005)$ & Length of residence & -0.421 & $-3.38(p<0.005)$ \\
\hline & & & 0.335 & $2.23(p<0.05)$ \\
\hline \multirow[t]{3}{*}{ Built environment } & $0.315(p<0.001)$ & Total non-residential property & 0.246 & $1.97(p<0.10)$ \\
\hline & & Places to sit outdoors & -0.052 & -0.43 (N.S.) \\
\hline & & sible street & -0.412 & $-3.20(p<0.005)$ \\
\hline \multirow[t]{4}{*}{ Transient environment } & $0.096(p<0.10)$ & (Home) crime prevention signs & 0.228 & $2.22(p<0.05)$ \\
\hline & & Block signs (public) & 0.123 & 1.07 (N.S.) \\
\hline & & Personalizations & -0.074 & -0.64 (N.S.) \\
\hline & & Graffiti on public property & 0.113 & 0.84 (N.S.) \\
\hline \multirow{3}{*}{ Territorial functioning } & $0.034(p<0.20)$ & Informal social control & 0.222 & $1.83(p<0.10)$ \\
\hline & & Neighbors watch after each other & 0.006 & 0.05 (N.S.) \\
\hline & $\mathbf{R}^{2}=0.692 ;$ Adj & $\mathrm{R}^{2}=0.595\left(\mathrm{~F}_{11,35}=7.15 ; p<0.00\right.$ & & \\
\hline
\end{tabular}

\footnotetext{
${ }^{*} n$ of blocks for Equations 1, 2 and $3=44 ; n$ of blocks for equations 4 and $5=47$; pair-wise deletion of missing data.

$\dagger$ Any non-residential property other than stores, schools, churches, offices or parking lots.N.S.

N.S., Not significant.
} 
Again, there was less victimization on more residentially stable blocks. In the next stage, three built environmental features added $15 \%$ more variance to the equation, mainly due to the influence of whether there was a school on the corner (final beta $=0.27, p<0.10$ ). Again representing the transient environment, dilapidated housing added $7 \%$ of the variance explained in criminal victimization. None of the territorial markers or subjective environmental variables warranted entry in this equation. The adjusted $\mathrm{R}^{2}$ for Equation 3 was $0.25(p<0.01)$.

Reported quality-of-life crimes. In Equation 4, three demographic variables were entered first; they explained $21 \%$ of the variance in quality-of-life crimes reported to the police during the year following the initial data collection. Next, four built environmental features added significantly to the equation (36\% more variance), due in largest part to the influence of non-residential property on the block (final beta $=-0.47, p<0.005$ ). Four transient environmental variables (three territorial markers and one incivility, litter) added 5\% (N.S.) more variance to the equation. Representing territorial functioning, informal social control did not contribute significantly to the equation, independent of the preceding predictors. As with the other four equations, none of the subjectively perceived incivilities warranted entry. The adjusted $R^{2}$ for Equation 4 was $0.50(p<0.0005)$.

Reported serious crime. In the final equation, length of residence and block population were entered first and together explained $25 \%$ of the variance in serious crimes reported to the police during the year following the initial data collection. Next, three built environmental features added $32 \%$ more variance to the equation, due in largest part to the influence of street visibility and width (final beta $=$ $-0.41, p<0.005$ ). The more narrow and visible the street, the lower the amount of reported crime. Four transient environmental variables (three territorial makers and graffiti on public property) added $10 \%$ more variance to the equation. The most influential of these was home crime prevention signs and stickers (e.g. "This house protected by Operation I.D.'). which were positively related to reported crime. Although the two territorial functioning variables contributed $3 \%$ more variance to the equation, independent of the preceding sets, this is mainly due to a suppression effect with informal social control. Again, none of the subjectively perceived incivilities warranted entry. The adjusted $R^{2}$ for Equation 5 was $0.60(p<0.0001)$.

\section{Discussion}

\section{Implications for theory and research}

There were three purposes of this study. The first was to present a more comprehensive conceptual framework of objective and subjective, permanent and transient, positive and negative environmental correlates of residential block street crime. The second purpose was to introduce a new, reliable instrument for objectively measuring the physical environment of residential blocks. The third purpose was to test the predictive validity of the conceptual framework and instrument.

The results supported many aspects of the framework. The objective built and transient physical environment were significantly and independently related to street crime and delinquency, even after controlling for key demographic variables. The significant environmental correlates varied with the particular crime indicator used (thus substantiating the importance of data triangulation when measuring crime).

Non-residential property was the strongest predictor of reported crime. As predicted by territoriality theory (Brown \& Altman, 1981; Taylor, 1988) but not by defensible space theory (Jacobs, 1961; Newman, 1972), the presence of stores, schools, and certain other common, non-residential buildings (i.e. multi-use blocks) were related to higher amounts of reported crime. This could be due to the use of such places by criminals (as part of their 'routine activity pattern') and/or the additional number of victim targets the places provide (i.e. non-resident complainants would be included in reported crimes but not in victimization or perceptions of crime and delinquency problems).

Defensible space theory is better supported by the finding that 'other' non-residential properties were related to reduced resident victimization and perceived crime and delinquency problems. A review of the completed Block Environmental Inventory forms reveals that this 'other' non-residential property category is dominated by open land uses (e.g. empty lots, public 'pocket' parks and gardens, public playgrounds). Apparently, it is this form of non-residential property that is associated with less victimization and perceived crime and delinquency problems. Although this is contrary to the hypothesis that criminals are attracted to such territorial 'gaps', we believe that public gardens and playgrounds may operate as well-used and protected 'secondary territories' on many of the blocks in the study (Brown \& Altman, 1981) and 
that they offer recreational opportunities for local youth. This idea is supported by evidence that public open space is related to greater interaction among neighbors in high-density neighborhoods (Fox et al., 1980).

As predicted, perceived crime and delinquency and serious reported crime were also significantly higher on streets that are wider and less visible from building interiors. Opportunities are fewer on such blocks for passive surveillance of the street, sidewalk and homes across the street. Wider streets may also invite more traffic, thus lending the block a more public character and making it more 'permeable' to criminals.

Several features in the objective transient environment (i.e. territorial markers and incivilities) were significantly related to one or more crime indicators, but many of these correlations were substantially reduced after partialling out demographic influences. Even fewer were significantly related to crime after controlling for built environmental influences. Two objective incivilities whose influence did not depend on either block demography or the 'permanent' environment were dilapidated housing (which predicted perceived delinquency problems and criminal victimization on the block) and litter (which predicted fewer quality-of-life crimes).

This last finding points toward another important outcome of this study which has to do with the portion of the framework that was not well supported by the data. Contrary to the disorder thesis, subjectively perceived incivilities were not strongly related to any of the crime indicators. In contrast to the results of Perkins et al. (1992), residents' passive perceptions of physical incivilities did not closely match trained raters' observations and were only modestly related to perceived and reported crime. It may be that residents, who see the incivilities daily, adapt behaviorally by avoiding use or become cognitively desensitized to it over time and do not see it as a problem unless it is new or greatly increased.

Offenders may view incivilities differently, but if they are similar to the actively observant raters in this study, they may be attracted to less littered blocks. Although none of the study blocks was greatly littered (according to the environmental assessment), the three blocks with the most litter all had only one reported quality-of-life crime. But even among the remaining blocks, those with more reported quality-of-life crimes typically had no objective litter problem. It is possible that criminals are actually less attracted to very littered blocks because they infer that there may be less valuable targets there. Although this finding contradicts the disorder, or 'broken windows', theory of crime (Skogan, 1990; Wilson \& Kelling, 1982), that theory gains support from the strong association between graffiti on public property and reported crime.

The development of our overall theoretical framework might benefit from exploring separate conceptual models for predicting block-level variation in police reports vs resident survey-based crime measures (victimization and perceived crime and delinquency problems), given the non-significant correlations between the two and the emergence of different environmental predictors for each. ${ }^{5}$ For example, blocks with more officially reported crime appear to be those with more commercial property (whose staff and patrons might also be more likely to report crimes to the police), more graffitti, a dense population, and fewer places to sit outdoorsi.e, a more 'urban' (as opposed to suburban/residential) environment. By contrast, the important predictors of the survey-based crime measures were environmental cues that more directly influence residents' cognitive (perception, concern) or emotional (fear, vulnerability) processes related to crime (Perkins et al., 1992). Evidently, these include poor visibility of the street, a lack of real barrier on the property, litter and dilapidated housing, and low perceived territorial functioning (informal social control, neighbors watching after each other).

\section{Implications for crime prevention}

Compared with perceived incivilities, the territorial functioning variables were more strongly, but not more consistently, related to crime. The perception that neighbors watch out for each other was related to having less of a perceived delinquency problem 15 months later. But blocks with greater perceived informal social control had more reported serious crime than other blocks the following year. Both of these effects hold up even after controlling for demographic and objective environmental influences; but it is possible that neither form of territorial functioning caused crime to go up or down. The relationship with perceived delinquency may be due to a kind of community perception 'halo effect'. It is likely that a pre-existing serious crime problem is why informal social control behaviors became necessary on a given block and that those behaviors include reporting crimes to the police. In fact, the correlation with informal social control does appear to be clearer on the high-crime blocks. The seven highest 'quality-of-life-crime' blocks and 10 of the 12 highest serious-crime blocks were at or above the mean in perceived informal social control. A study 
examining change in crime over time is needed, however, to determine whether informal social control, as a form of deliberate territorial functioning, can reduce crime.

Block demographics and the built environment shared most of the explained variance in each of the regression equations. Unfortunately for crime prevention purposes, they are also the most stable (i.e. difficult to change) variables in the framework. Residents themselves may be able to trim trees and shrubbery in order to improve street visibility. But the types of existing non-residential property, the width of the street and the demographic composition of the community are unlikely to change much in the near future.

Still, even this information can be used in future planning by both individuals and those involved in urban planning, zoning, housing and land use development. For example, our results suggest that residents of transient and high mobility (e.g. 'stepping stone') neighborhoods (even newly gentrified areas; Taylor \& Covington, 1988) may experience more crime problems. Furthermore, the finding that commercial property tends to attract crime and delinquency problems could provide further rationale for planning recreational land use (parks and playgrounds) that are well designed, maintained, and used, along with other defensible space features, to accompany both new and existing commercial settings.

The display and maintenance of territorial markers represent another environmental approach to crime prevention that can be taken by residents themselves. Crime prevention signs on residents' homes was the only territorial marker to remain a significant crime factor after controlling for block demography and the built environment. Contrary to our hypothesis, such signs were indicative of blocks with more reported serious crime. Although unpredicted, this was not surprising for two reasons. 'Block Watch', 'Operation I.D.' and the other community crime prevention programs symbolized by these signs are initiated in concert with police in response to serious local crime problems, which are rarely significantly reduced by them (Rosenbaum, $1986,1988)$. In addition, such programs often encourage residents to report crimes that occur which could lead to a wave of reported crime without any change in actual crime occurrence.

The present results neither support nor refute the effectiveness of existing community policing or civilian crime prevention efforts. But they do suggest that crime control and other community development strategies should not overlook the importance of building and using recreational space and reducing incivilities, such as dilapidated housing and litter.

\section{Constraints on generalizability}

There are certain limitations in generalizing from the present study. Caution should be taken when generalizing across the three demographically different neighborhoods in this study and when generalizing from them to other kinds of communities. Some of the atypical features of the sample include: (a) two out of three neighborhoods which were low-income or working-class and minority yet had a large proportion of homeowners; (b) all neighborhoods had been experiencing increasing rates of reported crime at a time when city-wide rates were holding steady or declining; and (c) a housing density and architectural style that is more crowded and 'urban' that most suburban areas but less than most of the rest of New York City or other large inner-city residential areas.

The sample is not unique, however. Each of these characteristics describes the growing 'inner ring' of poor and working-class neighborhoods that are now surrounding the refurbished and gentrified center cities of America. With regard to the rising crime rate, crime had generally increased in most urban areas over the past 30 years. The brief and slight downward trend in the early to mid-1980s, just prior to the collection of these data, was more of an anomaly than the upward pattern in the present sample.

\section{Future research}

Additional environmental constructs and measures are needed to enhance our understanding of the physical context of crime. The finding that perceived and actual physical incivilities were not closely related is contrary to results by Perkins et al. (1992) who used similar, but not identical, methods in a study of 50 Baltimore blocks. It underscores the importance of objectively and independently measuring the physical environment and suggests that future research should continue to measure both the subjective and objective community environment in different ways and investigate the locus of any differences in the results obtained. One approach to untangling such differences would be to combine quantitative survey, environmental and archival data with more qualitative field observations and in-depth interviews with local residents to obtain information on use of space (e.g. avoidance) and cognitive densensitization. 
The vast majority of psychological research is based on individual-level analyses that often confuse individual and group-level effects (Shinn, 1990). This study focused on block-level effects, but did not provide a direct and simultaneous comparison of effects at the two different levels. This study also found that there may be important neighborhoodlevel effects that were treated here as block-level demographic effects. Future community-based research should allow for teasing out effects at all the relevant levels of analysis.

Even in this longitudinal study, the interactive nature of the relationship between the more transient and especially the subjective environment, on the one hand, and crime and other community social phenomena, on the other, makes it difficult to determine which causal direction predominates at any given time or place or with any given variable. Although the nature of some variables as stable and others as more transient helped in the interpretation of the present results, more research should be conducted quasi-experimentally (Cook \& Campbell, 1979). Using identical pre- and post-measures of both crime and the environment and manipulating environmental features in the interim (cf. Fowler \& Mangione, 1986) would help sort out the problem of causal direction between crime and its transient environmental context.

The present study found that various permanent physical features are strongly related to street crime. It also suggests that changes in the transient and perceived environment should not be a major focus of crime prevention efforts. These more malleable aspects of the community environment can have an impact on the social climate of a block or neighborhood, however, and may elicit greater participation in more general (non-crime-related) community development activities (Perkins, 1990).

\section{Notes}

(1) Portions of this article are based on Douglas D. Perkins' unpublished dissertation in Community Psychology at New York University. The data are part of the Block Booster Project which was funded by the Ford Foundation and administered by the Citizens Committee for New York City. The authors thank David M. Chavis and Paul Florin for their invaluable contributions to the Project and Barbara B. Brown, Marybeth Shinn and the anonymous reviewers for extremely helpful comments on a previous draft of this article. The dissertation was supervised by Barbara Felton and Marybeth Shinn and supported by the National Institute of Justice and the Society for the Psychological Study of Social Issues.

(2) All correspondence should be sent to: Douglas D.
Perkins, Environment and Behavior Area, FCS Department, University of Utah, Salt Lake City, UT 84112, U.S.A.

(3) The latest version of the Block Environment Inventory is available from Douglas D. Perkins. After a brief training session, two graduate research assistants and the author conducted a pilot test on 10 non-study blocks in two of the three study neighborhoods. Discussion of judgement rules was allowed between pilot blocks but not while rating a block, and no ratings were allowed to be changed based on post hoc discussions. Descriptive statistics and inter-rater reliability coefficients (based on pilot blocks) for the environmental inventory can be found in Table 1. The percentage of exact three-way agreement for block-level items was computed at the block level $(n=10)$ and agreement for property-level items was computed at the property level $(n=48)$. Because percentage agreement can be spuriously high for variables with low variance, all block-level total count items with any variance on the pilot test were further tested using the mean of the three block-level inter-rater product moment correlations, all of which were above the mean $r(0.90)$. The mean inter-rater correlation for the items used for the present study was 0.79 . Two items (vandalism and decorations) were excluded on the basis of weak interrater reliability. Thus, although the raters were still learning the instrument and how to apply it during the pilot tests, inter-rater agreement was found to be strong for most items used in the present analyses and was acceptable for the overall measure.

(4) Four blocks were dropped due to changes in their block associations, which were important to the larger project. The other reason for the smaller sample of follow-up survey respondents is that cost limitations required sampling fewer respondents per block.

(5) We gratefully acknowledge an anonymous reviewer for drawing our attention to this.

\section{References}

Ahlbrandt, R. \& Cunningham, K. J. (1979). A New Policy for Neighborhood Preservation. New York, NY: Praeger.

Becker, F. D. (1977). Housing Messages. Stroudsburg, PA: Dowden.

Brantingham, P. J. \& Brantingham, P. L. (Eds) (1981). Environmental Criminology. Beverly Hills, CA: Sage.

Brower, S., Dockett, K. \& Taylor, R. B. (1983). Residents' perceptions of site-level features. Environment and Behavior, 15, 419-437.

Brown, B. B. (1987). Territoriality. In D. Stokols \& I. Altman, Eds., Handbook of Environmental Psychology. New York, NY: Wiley, vol. 2, 505-531.

Brown, B. B. \& Altman, I. (1981). Territoriality and residential crime. In P. J. Brantingham \& P. L. Brantingham, Eds., Environmental Criminology. Beverly Hills, CA: Sage, pp. 5676.

Brown, B. B. \& Altman, I. (1983). Territoriality, defensible space and residential burglary: An environmental analysis. Journal of Environmental Psychology, 3, 203-220.

Brown, B. B. \& Perkins, D. D. (1992). Disruptions in place attachment. In I. Altman \& S. Low, Eds., Place Attachment, Vol. 12, Human Behavior and Environment. New York, NY; Plenum, pp. 279-304. 
Brown, B. B. \& Werner, C. M. (1985). Social cohesiveness, territoriality and holiday decorations: The influence of cul-desacs. Environment and Behavior, 17, 539-565.

Cohen, J. (1969). Statistical Power Analysis for the Behavioral Sciences. New York, NY: Academic Press.

Coleman, A. (1989). Disposition and situation: two sides of the Same Crime. In D. Evans \& D. Herbert, Eds., The Geography of Crime. London: Routledge, pp. 108-134.

Cook, T. D. \& Campbell, D. T. (1979). Quasi-experimentation: Design \& Analysis Issues for Field Settings. Boston, MA: Houghton Mifflin.

Craik, K. H. \& Appleyard, D. (1980). Streets of San Francisco: Brunswick's lens model applied to urban inference and assessment. Journal of Social Issues, 36, 72-85.

Fowler, F. J. \& Mangione, T. W. (1986). A three-pronged effort to reduce crime and fear of crime: The Hartford Experiment. In D. P. Rosenbaum, Ed., Community Crime Prevention: Does it Work? Beverly Hills, CA: Sage.

Fox, B. J., Fox, J. \& Marans, R. W. (1980). Residential density and neighbor interaction. The Sociological Quarterly, 21, 349-359.

Gans, H. J. (1967). The Levittowners: Ways of Life and Politics in a New Suburban Community. New York, NY: Random House.

Greenberg, S. W. \& Rohe, W. M. (1984). Neighborhood design and crime: A test of two perspectives. Journal of the American Planning Association, 50, 48-61.

Greenberg, S. W. \& Rohe, W. M. (1986). Informal social control and crime prevention in modern urban neighborhoods. In R. B. Taylor, Ed., Urban Neighborhoods: Research and Policy. New York, NY: Praeger.

Greene, J. R. \& Taylor, R. B. (1988). Community-based policing and foot patrol: Issues of theory and evaluation. In J. R. Green \& S. D. Mastrofski, Eds, Community Policing: Rhetoric or Reality? New York, NY: Praeger.

Harries, K. D. (1974). The Geography of Crime and Justice. New York, NY: McGraw-Hill.

Hunter, A. (1987). Symbolic Communities. Chicago, IL: University of Chicago Press.

Jacobs, J. (1961). The Death and Life of Great American Cities. New York, NY: Random House.

Kenny, D. A. \& Lavoie, L. (1985). Separating individual and group effects. Journal of Personality and Social Psychology, 48, 339-348.

Latane, B. \& Darley, J. M. (1969). Bystander apathy. American Scientist, 57, 244-268.

Levine, J. (1976). The potential for crime over-reporting in crime victimization surveys. Criminology, 214, 307-330.

Lewis, D. \& Maxfield, M. (1980). Fear in neighborhoods: An investigation of the impact of crime. Journal of Research on Crime and Delinquency, 17, 160-179.

Lewis, D. A. \& Salem, G. W. (1985). Fear of Crime: Incivility and the Production of a Social Problem. New Brunswick, NJ: Transaction.

MacDonald, J. E. \& Gifford, R. (1989). Territorial cues and defensible space theory: The burglar's point of view. Journal of Environmental Psychology, 9, 193-205.

Maxfield, M. G. (1987). Incivilities and fear of crime in England and Wales and the United States: a comparative analysis. Paper presented at the Annual Meeting of the American Society of Criminology, Montreal.

Merry, S. E. (1981). Urban Danger: Life in a Neighborhood of Strangers. Philadelphia, PA: Temple University Press.
Newman, O. (1972). Defensible Space: Crime Prevention Through Urban Design. New York, NY: Macmillan.

Newman, O. \& Franck, K. (1982). The effects of building size on personal crime and fear of crime. Population and Environment, 5, 203-220.

O'Brien, R. M. (1985). Crime and Victimization Data. Beverly Hills, CA: Sage.

Perkins, D. D. (1990). The social and physical environment of residential blocks, crime, and citizens' participation in block associations. Unpublished Doctoral Dissertation. Department of Psychology, New York University.

Perkins, D. D., Florin, P., Rich, R. C., Wandersman, A. \& Chavis, D. M. (1990). Participation and the social and physical environment of residential blocks: Crime and community context. American Journal of Community Psychology, 18, 83-115.

Perkins, D D., Meeks, J. W. \& Taylor, R. B. (1992). The physical environment of street blocks and resident perceptions of crime and disorder: Implications for theory and measurement. Journal of Environmental Psychology, 12, 21-34.

Reppetto, T. (1974). Residential Crime. Cambridge, MA: Ballinger. Rich, R. (1980). Dynamics of leadership in neighborhood organizations. Social Science Quarterly, 60, 570-587.

Rosenbaum, D. P. (1986). Community Crime Prevention: Does it Work? Beverly Hills, CA: Sage.

Rosenbaum, D. P. (1988). Community crime prevention: a review and synthesis of the literature. Justice Quarterly, 5, 323-395.

Shinn, M. (1990). Mixing and matching: levels of conceptualization, measurement, and statistical analysis in community research. In P. Tolan, C. Keys, F. Chertok \& L. Jason, Eds., Researching Community Psychology: Integrating Theories and Methods. Washington, D.C.: American Psychological Association, pp. 111-126.

Shumaker, S. A. \& Taylor, R. B. (1983). Toward a clarification of people-place relationships: A model of attachment to place. In N. R. Feimer \& E. S. Geller, Eds., Environmental Psychology: New Directions and Perspectives. New York, NY: Praeger.

Skogan, W. G. (1990). Disorder and Decline. New York, NY: Free Press.

Skogan, W. \& Maxfield, M. (1981). Coping with Crime: Individual and Neighborhood Reactions. Beverly Hills, CA: Sage.

Taylor, R. B. (1987). Toward an environmental psychology of disorder: Delinquency, crime, and fear of crime. In D. Stokols \& I. Altman, Eds., Handbook of Environmental Psychology. New York, NY: Wiley, vol. 2, 951-986.

Taylor, R. B. (1988). Human Territorial Functioning: An Empirical, Evolutionary Perspective on Individual and Small Group Territorial Cognitions, Behaviors and Consequences. Cambridge: Cambridge University Press.

Taylor, R. B. \& Covington, J. (1988). Neighborhood changes in ecology and violence. Criminology, 26, 553-589.

Taylor, R. B. \& Gottfredson, S. D. (1986). Environmental design, crime, and prevention: an examination of community dynamics. In A. Reiss \& M. Tonry, Eds., Communities and Crime. Chicago: University of Chicago Press, pp. 163-202.

Taylor, R. B., Gottfredson, S. D. \& Brower, S. (1984). Block crime and fear: defensible space, local social ties, and territorial functioning. Journal of Research in Crime and Delinquency, 21, 303-331.

Taylor, R. B. \& Hale, M. (1986). Testing alternative models of fear of crime. Journal of Criminal Law and Criminology, 77, 151-189. 
Taylor, R. B., Shumaker, S. \& Gottfredson, S. (1985). Neighborhood-level links between physical features and local sentiments. Journal of Architectural Planning and Research, 2, 261-275.

Taylor, R. B. \& Stough, R. R. (1978). Territorial cognition. Assessing Altmans typology. Journal of Personality and Social Psychology, 36, 418-422.
White, G. F. (1990). Neighborhood permeability and burglary rates. Justice Quarterly, 7, 57-67.

Wilson, J. Q. \& Kelling, C. (1982). The police and neighborhood safety: Broken windows. Atlantic, 127, 29-38.

Yates, D. (1973). Neighborhood Democracy. Lexington, MA: Heath. 